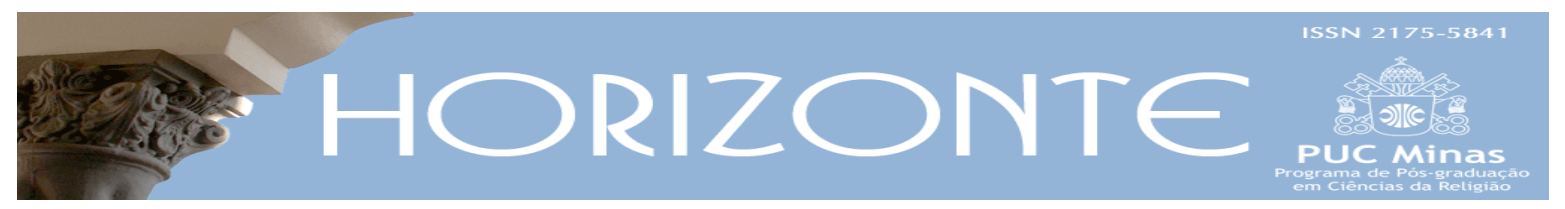

Dossiê: Religião e Educação - Artigo original (c) (1)

DOI - 10.5752/P.2175-5841.2020v18n55p174

\title{
Cuidado e conhecimento: formação humana e relação dialógica em ambientes educacionais
}

\author{
Care and knowledge: \\ human formation and dialogical relationship in educational environments
}

Roberlei Panasiewicz*

\begin{abstract}
Resumo
O processo educacional atual enfrenta desafios variados, pois lida com relações e inteligências múltiplas. A educação escolar participa destes desafios. Como educar para a tolerância e para a responsabilidade social, tendo em vista a construção da cultura de paz, do respeito e do cuidado com o diferente? Como a disciplina de Ensino Religioso pode participar ativamente deste processo de formação humana? Este estudo faz parte de uma pesquisa mais ampla sobre tolerância e promoção da cultura de paz em algumas escolas públicas de Ensino Fundamental da periferia da cidade de Belo Horizonte/MG; e, baseada na investigação bibliográfica e observacional, visa pensar uma ação pedagógica com foco dialógico. Denominamos de "pedagogia do cuidado e do conhecimento", pois afeto e saberes devem coexistir no ambiente escolar para estimular relações construtivas. Esta reflexão objetiva apresentar resultados desta pesquisa e propor o cuidado nas relações interpessoais, para que a escola atinja índices de qualidade desejáveis, tanto no nível intelectual quanto emocional. Relações dialógicas são construídas na valorização do humano e por isto permanecem. O exercício do diálogo inter-religioso no ambiente escolar pode ser oportunidade e treinamento de construções dialógicas, tanto ao participar de projetos escolares quanto ao serem praticados no interior da sala de aula.
\end{abstract}

Palavras-chave: Cuidado. Conhecimento. Educação. Relação Dialógica.

\begin{abstract}
The current educational process faces multiple challenges, as it deals with relationships and with multiple intelligences. School education participates in these challenges. How to educate for the tolerance and social responsibility, taking into account the construction of a culture of peace, respect and care towards the difference? How could the discipline of Religious Education actively participate in the process of human formation? This study is part of a broader research on tolerance and promotion of a culture of peace in some public elementary schools in the suburbs of the city of Belo Horizonte / MG. Based on bibliographic and observational research, the study aims to conceive a pedagogical action with a dialogical focus. This action was called "pedagogy of care and knowledge", since affection and knowledge need to coexist in the school environment to encourage constructive relationships. This reflection aims to present the results of the aforementioned research and propose care in interpersonal relationships, so that the school reaches desirable quality level, both at the intellectual and emotional levels. Dialogical relationships are built on valuing the human and for this very reason they remain. The exercise of interreligious dialogue in the school environment can be an opportunity and training in dialogical constructions, both by participating in school projects and in their development inside the classroom.
\end{abstract}

Keywords: Care. Knowledge. Education. Dialogical Relationship.

Artigo submetido em 18 de dezembro de 2019 e aprovado em 20 de abril de 2020.

* Doutor em Ciência da Religião pela UFJF. Professor da PUC Minas. País de origem: Brasil. E-mail: roberlei@pucminas.br 


\section{Introdução}

A educação escolar é fundamental no processo de formação e de desenvolvimento das sociedades. Ela possibilita que o ser humano cresça de forma autônoma e crítica em conformidade com seu jeito de ser. Habilidades e competências, que são construídas, estimulam este humano a entrar em conexão consigo, com o outro, com o cosmos e a desenvolver sua espiritualidade, enfim, a se descobrir profundamente relacional. Para que isso ocorra, a qualidade do ensino embasa todo o processo. Ela perpassa a capacitação técnica, o reconhecimento financeiro dos profissionais da área - isso também implica o estímulo a mais pessoas buscarem ser professor - e pelo afeto que deve balizar a relação educadoreducando. Somente uma educação que tenha como prioridade o cuidado nas relações interpessoais alcançará qualidade com níveis desejáveis de desenvolvimento para o país. Qualidade significa que tanto educador quanto educando se sentem realizados nas atividades em que se propuseram engendrar juntos. Construir relações saudáveis implica criar ambientes leves, comprometidos e integrados com a comunidade local. Assim, o processo educacional deve levar em conta aspectos existenciais, intelectuais, sociais e econômicos dos envolvidos.

Estes apontamentos e a presente reflexão resultam de uma pesquisa mais ampla sobre tolerância e promoção da cultura de paz, feita em algumas escolas estaduais da periferia da cidade de Belo Horizonte/MG. ${ }^{1}$ Concretamente, a pesquisa investigou 4 escolas públicas estaduais do Ensino Fundamental II, da região oeste, e que se encontravam - segundo dados do Centro Integrado de Informações de Defesa Social (CINDS), da Secretaria de Estado de Defesa Social de Minas Gerais,

\footnotetext{
${ }^{1}$ Esta pesquisa teve duração de dois anos (início do segundo semestre de 2017 a final do primeiro semestre de 2019) e foi composta pela seguinte equipe: Roberlei Panasiewicz (doutor - coordenador), Izabella Faria de Carvalho (doutora), Camila Campos M. da Cruz (mestre), Dinéia Fontoura Gonçalves (mestre), Adilson do Nascimento Ferreira (mestrando) e as bolsistas de Iniciação Científica Júlia Cotta Lima de Oliveira (Pibic/Pibiti-Cnpq), Júlia Edmundo Moss (Fapemig) e Bruna Gabriele Oliveira (Fapemig). Para sua realização teve os seguintes financiamentos: FAPEMIG; FIP/PIBIC-CNPq; PUC Minas.
} 
de 2010 - localizadas em uma das regiões com maior índice de registro de violência de Belo Horizonte e região Metropolitana. ${ }^{2}$

O objetivo (inicial) visava compreender como a formação humanista fazia parte do processo educacional em escolas da periferia e em situações de violência da Região Metropolitana de Belo Horizonte. Daí em diante, pensar como educar para a tolerância e para a responsabilidade social a partir destes ambientes, com vistas à construção da cultura de paz, do respeito e do cuidado com o diferente.

Esta reflexão se propõe a apresentar alguns resultados e a apontar alguns encaminhamentos para o processo educacional, em especial para as escolas de periferia e em situação de violência. Não focaremos no aspecto da formação técnica e nem na remuneração do profissional da educação, essencial para o bom desenvolvimento da profissão, mas não foi o foco deste estudo. Assim, a tese que surgiu da pesquisa indica que somente uma educação que tenha por princípio o cuidado nas relações interpessoais terá índice de qualidade desejável, tanto intelectual quanto emocional, para qualquer instituição de ensino desenvolvida. Este artigo e explicitação desta tese serão feitos em quatro momentos. Primeiramente serão apresentados aspectos metodológicos da pesquisa, procurando explicitar passos e reconstruções a partir das observações percebidas. Em seguida, faremos um exercício de repensar as práticas pedagógicas em busca de novas reconstruções teóricas. Em terceiro lugar, proporemos um dado essencial que emergiu da pesquisa: a articulação entre cuidado e conhecimento para o desenvolvimento do processo de ensino-aprendizagem. Por fim, discutiremos a linguagem como expressão do afeto e do conhecimento. A educação, para ser bemsucedida em sua atuação, deve ser essencialmente afetuosa em seu exercício de construção do conhecimento.

\footnotetext{
${ }^{2} \mathrm{O}$ termo violência tem variados aspectos e categorizações. Trabalhamos a compreensão da violência como um problema social, conforme proposto por Maria Cecília de Souza Minayo (2006). Assim, o conceito se amplia e violência passa a ser compreendida não somente como agressão propriamente física, mas articula três aspectos: privação de recursos, falta de oportunidades e baixa produção de riquezas.
} 


\section{Metodologia: escolas em movimento}

A clareza dos métodos e técnicas torna-se fundamental em qualquer pesquisa. Clareza, aqui, não significa conhecimento fechado ou noção prévia de todos os passos a serem dados; implica abertura para saber que estes passos podem ser alterados em prol do avanço da pesquisa. Trata-se de abertura metodológica para maior conhecimento da realidade pesquisada. A etimologia deste termo pode nos ajudar a compreender melhor este momento. Metodologia vem de methodos (grego) ou methodus (latim) e indica um caminho para chegar a um fim ou a um determinado resultado. Algumas vezes, o caminho está visivelmente perceptível, outras, há pouca nitidez e o resultado está em aberto; os passos serão construídos a cada nova trilha encontrada. Por isso, o indicativo do rumo e a abertura para discernir o processo tornam-se fundamentais para a construção de cada etapa. Esta pesquisa não foi diferente. O objetivo, como anunciado, era compreender como a formação humanista fazia parte do processo educacional de escolas da periferia e em situações de violência da Região Metropolitana de Belo Horizonte e, a partir daí, repensar formas de educar para a tolerância e para a responsabilidade social, almejando a construção da cultura de paz, do respeito e do cuidado com o diferente. Para tanto, houve necessidade da investigação de documentos para captar como cada escola percebia e registrava a formação humanista. Destes, foram priorizados os Projetos Políticos Pedagógicos (PPP's), os temas transversais e os Planos de Ensino da disciplina Ensino Religioso. Para além dos documentos, a observação participativa se apresentou como outro caminho viável para a percepção das práticas humanistas no cotidiano escolar.

A construção dinâmica deste "caminho" seguiu cinco etapas, que serão descritas brevemente. 3 A primeira etapa foi destinada ao estudo sobre o conceito de violência, ao aprofundamento do sentido de Projeto Político Pedagógico (PPP), sobre área de ponderação e escolha da faixa etária/ensino e das escolas situadas em áreas consideradas violentas. A segunda etapa foi dedicada a estabelecer contato

\footnotetext{
${ }^{3}$ Duas comunicações ocorridas no Congresso da Soter, em 2018, em Grupos de Trabalhos (GTs) distintos, apresentam facetas das etapas da construção desta pesquisa, como a metodologia aplicada e alguns referenciais teóricos; ver Cruz; Gonçalves; Panasiewicz (2018, p. 658-664); Carvalho; Ferreira (2018, p. 1508-1513).
} 
com as escolas selecionadas para uma visita técnica e coleta do material, a saber, os PPPs e os planos de ensino da disciplina Ensino Religioso. A terceira etapa foi voltada para a análise deste material e a construção de tabelas das escolas para cruzamentos de informações. E, em seguida, a quarta etapa, devolução das constatações (iniciais) feitas para escolas participantes. Este momento foi fundamental para o rumo da pesquisa. 4 À medida que os professores e diretores das escolas reagiam à apresentação da equipe, fomos percebendo uma dicotomia entre a realização de projetos pedagógicos, desenvolvidos nas escolas, e a concepção de construção do conhecimento propriamente dito. Foi justamente sobre esta dicotomia que a equipe se dedicou a compreender na quinta etapa. A sexta etapa foi a realização de um Seminário em uma escola, com convite a todas as demais escolas envolvidas sobre um tema que denominamos "Pedagogia do Cuidado e do Conhecimento", que é o tema da presente reflexão. Por fim, a sétima e última etapa foi destinada à avaliação de todo o percurso realizado.

Trata-se, portanto, de quatro escolas estaduais, situadas no oeste da região Metropolitana de Belo Horizonte. Optamos pelo ensino fundamental II, por esperarmos que nessa fase o aluno já tenha desenvolvido competências fundamentais para refletir a respeito de seu lugar no mundo, obtendo uma maior familiaridade com conteúdos humanistas. Estes conteúdos, provavelmente, estão mais desenvolvidos nos materiais didáticos desta etapa do ensino. O objetivo inicial da pesquisa era, a partir da coleta do material (PPPs e planos de ensino), compreender como a formação das humanidades estava presente nas escolas da periferia em ambientes violentos e ajudar a pensar como esta formação poderia se destacar na disciplina Ensino Religioso, mas também perpassar e se conjugar de forma efetiva com os temas transversais.5 Entretanto, a quarta etapa foi transformadora para a equipe e houve mudança de rota. Portanto, o que houve nesta etapa?

\footnotetext{
${ }^{4}$ Para estas análises, tivemos como pressuposto uma pesquisa anterior sobre Educação e Cidadania, que procurou avaliar a formação humanista da juventude nos PPPs; ver: Panasiewicz; Baptista; Braga; Carneiro (2012, p. 399-431).

${ }^{5}$ Nessa perspectiva de compreender a "educação como espaço de construção da condição humana", para além da formação técnica, pode-se dizer que "tal posição considera que o Ensino Religioso tem sentido na perspectiva laica, portanto, não como lugar de ensino de religião ou de doutrinação, mas elemento da cultura e da crítica, com sua dimensão cognitiva e informativa, como as demais ciências, mas também formativa, na perspectiva da fundamentação antropológica, dos valores e dos sentidos da existência, da 'cultura das humanidades'". (BAPTISTA, 2015, p. 117).
} 
A constatação da dicotomia existente na consciência e nas atitudes práticas dos professores e diretores entre a realização de projetos pedagógicos - sejam eles propostos pela Secretaria de Educação, sejam promovidos pela própria escola, com o intuito de dialogar com a comunidade em seu entorno e com empresas parceiras -, e o conhecimento vindo através das disciplinas lecionadas nas salas de aula, propiciou mudança de rota e a seguinte questão para a equipe: como Projetos (práticos) e Conhecimentos (teóricos) podem estar articulados nos ambientes escolares? A presença da equipe nas escolas observando a realização destes projetos levou a releituras e ao estudo da Pedagogia de Projetos e de Projetos de Trabalho. Entretanto, estas Pedagogias também pareciam não responder suficientemente aos desafios percebidos. Por que não? Quais os novos estudos e encaminhamentos? Essas perguntas foram fundamentais para a compreensão da relação ensinoaprendizagem, teoria e prática e formação humanista, que procuraremos explicitar.

\section{Repensar a prática pedagógica}

A situação de violência no entorno das escolas e a maneira como os professores lidam com crianças e adolescentes com pouca experiência de afeto desafiam qualquer educador. Como auxiliar estes educadores a serem afetuosos com as crianças e, ao mesmo tempo, poder relacionar conhecimento intelectual com os projetos práticos desenvolvidos nas escolas? Esta pergunta perpassou a anterior e entrou em sintonia, provocando atualização da proposta da pesquisa: como o processo educacional lida com conteúdos e humanidades de forma a gerar novas pessoas cidadãs?

É preciso pensar e viver a educação como meio democrático e, nesta trajetória, possibilitar o ser humano a se tornar cada vez mais autônomo e protagonista do seu processo de construção de conhecimento. Processo que deve ser pautado em condutas que permitam formar um cidadão ético, que respeite a liberdade religiosa, que caminhe para a tolerância e para a responsabilidade social, visando à construção da cultura de paz, do respeito e do cuidado com o diferente. 
Assim, como pensar e vivenciar pedagogias que lidem com projetos e respondam às necessidades das escolas da periferia? Esta pergunta pode ser respondida por estudos de educadores como John Dewey, Paulo Freire e Fernando Hernandéz. Apontaremos, brevemente, algumas pistas dadas por eles, que ajudaram a compreender a prática pedagógica das escolas pesquisadas, porém, não são foco de análise neste momento. Como bem sintetizou Kishimoto (2011), John Dewey (1859-1952), filósofo da educação, "defende a democracia e a liberdade de pensamento como condição para o desenvolvimento intelectual e emocional das crianças, batalha pelo pensamento crítico, focaliza a prática [...]” e, ao compreender que as ideias têm propósitos instrumentais, "torna-se um dos expoentes do pragmatismo, por ele denominado instrumentalismo, porque busca as ideias como instrumento para a resolução de problemas reais”. Para Dewey, o desenvolvimento deve atingir os aspectos físico, emocional e intelectual das crianças. Quanto mais as crianças forem estimuladas a fazer a experiência, maior será o interesse e aprenderão a pensar por si mesmas.

Paulo Freire (1921-1997) é considerado um ícone da educação brasileira e possui reconhecimento internacional pelo seu método de alfabetização de adultos, mas também por ter desenvolvido um pensamento pedagógico crítico e com viés político. Preocupado com os empobrecidos da sociedade, constrói um método educacional que possibilite o educando a entender sua situação de opressão e, sobretudo, agir em favor da própria libertação e dos que estão ao seu redor. Afirma, na Pedagogia do Oprimido, que "ninguém liberta ninguém, ninguém se liberta sozinho: os homens se libertam em comunhão" (FREIRE, 1974, p. 29). Em 2012 foi reconhecido como o Patrono da Educação Brasileira (Lei n. 12.612, de 13 de abril).

Fernando Hernandéz (1952) propõe reorganizar o currículo escolar e passar das disciplinas para projetos de trabalho. Esta tarefa deve ser feita através da atuação conjunta de professores e alunos. Nesta dinâmica, o professor deve se transformar em um pesquisador/mediador e o aluno, por sua vez, passa a ser o sujeito de uma situação de aprendizagem; o ponto de partida é a dúvida geradora por determinado assunto. Ele compreende que pensar a educação através de 
projetos de trabalho é mais do que uma proposta metodológica; trata-se de outra concepção de ensino. Os Projetos de Trabalho pretendem repensar a relação entre conhecimento e currículo e buscam articular experiências fora da escola com a construção das identidades dos alunos.

Nessa maneira de conceber a Educação, os estudantes:

a) participam num processo de pesquisa que tem sentido para eles e elas (não porque seja fácil ou porque gostem dele) e em que utilizam diferentes estratégias de pesquisa;

b) podem participar no processo de planejamento da própria aprendizagem $\mathrm{e}$

c) são ajudados a serem flexíveis, reconhecer o "outro" e compreender seu próprio entorno pessoal e cultural. (HERNANDÉZ, 1998, p. 86).

Tanto a pedagogia de projetos quanto a pedagogia de trabalho são propostas revolucionárias para o ensino-aprendizagem. Porém, para a realidade observada, a pedagogia de projetos não responde com satisfação, pois a questão geradora parte, essencialmente, do professor. A pedagogia de trabalho também apresenta dificuldades devido à estrutura curricular que as escolas estaduais devem seguir. Entretanto, são pedagogias que, sem dúvida, devem participar do cotidiano das escolas, pois transformam a relação ensino-aprendizagem. Deste desafio surgiu a proposta que, em certo sentido, antecede e se estende pelo ambiente escolar, de modo particular, o espaço interno das salas de aula. Trata-se de pensar e praticar uma "pedagogia do cuidado e do conhecimento". Qual a sua proposta? Ela visa pensar uma ação educativa que propicie a interação professor-aluno-projeto, que articule ação com conhecimento, porém, centrada no cuidado. Partimos do pressuposto de que o afeto é fundamental em toda relação humana e essencial no processo do ensino-aprendizagem, pois mantém esta articulação. Sem afeto não há aprendizagem, apesar de poder existir assimilação de conteúdo. $O$ afeto, da parte dos professores, estimula os alunos a entrarem na dinâmica da situação-problema; o afeto, da parte dos alunos, faculta os professores a serem melhores mediadores e buscadores do conhecimento. 
Pensar em uma pedagogia do cuidado e do conhecimento é pensar em ação educativa que propulsiona o aluno a ser protagonista do seu processo de aprendizagem e, na dinâmica do levantar dúvidas, promova pesquisa, recrie relações interpessoais e, neste processo, propicie o desenvolvimento do saber. Este conjunto de abordagens e conhecimentos deve favorecer tanto professores quanto alunos a desenvolverem valores morais e éticos que colaborem para a construção de um sujeito tolerante e ciente de sua responsabilidade educacional e social. O conhecimento não pode estar afastado de seu compromisso ético. Por isso, num primeiro momento e a partir da realidade observada, compreendemos que há necessidade do "cuidar de quem cuida": o cuidado e o afeto com os professores refletirão diretamente no compromisso ético e no processo de ensino-aprendizagem.

Cuidar de quem cuida impulsiona a relação professor-aluno para que ser torne cada vez mais humanizante. Juntamente com habilidades técnicas, há necessidade de uma formação constante dos educadores para o cuidado, para o diálogo, para a tolerância e para a cidadania. Desta forma, compreendemos que estarão ainda mais capacitados para estimular o processo de ensino-aprendizagem, sobretudo, em ambientes violentos. Saber como acolher uma criança ou um adolescente numa situação de pouco afeto é potencializá-lo para que ele faça diferença em seu convívio, seja no ambiente escolar, familiar ou social. ${ }^{6}$ Entretanto, como compreender a relação entre cuidado e conhecimento?

\section{Cuidado e conhecimento}

De maneira geral, as pesquisas relacionadas ao tema do cuidado remetem, sobremaneira, à área da saúde e relatam a atenção deste profissional com seus pacientes. Esta abordagem é fundamental, pois aponta para a centralidade do humano e de sua saúde. Entretanto, trataremos aqui de aspectos mais amplos do termo e como este conceito pode ajudar a pensar o processo educacional e a relação professor-aluno. O cuidado será compreendido como substantivo, ou seja, enquanto

\footnotetext{
${ }^{6}$ Pesquisa similar foi desenvolvida por Bristott; Kripka; Bedin (2017), trabalhando no ambiente educacional e destacando o cuidado com os professores e com os funcionários.
} 
nomeia sentimentos, noções, qualidades, e não como adjetivo, que caracteriza o substantivo atribuindo qualidade, característica ou aspecto. Enquanto adjetivo, o termo também é importante, porém, não resguarda a mesma força. Podemos, por exemplo, dizer: "Se recortarmos as folhas com cuidado, as salas ficarão limpas": qualifica, porém, não tem força transformadora. Agora, se dissermos: "O cuidado é essencial para termos crianças saudáveis e educadas" muda a perspectiva e a palavra se torna profundamente transformadora e provocadora de novas atitudes. É neste sentido que pensaremos o termo "cuidado".

Leonardo Boff é um teólogo brasileiro e se dedicou a estudar e a escrever sobre o cuidado. Fez ampla pesquisa do termo e ao trabalhar com os escritos do filósofo Martin Heidegger (1889-1976) - que por sua vez retoma escritos de Aristóteles, Santo Agostinho e das Epístolas de São Paulo - ele conclui dizendo:

O cuidado entra na definição essencial do ser humano. Constitui a base para qualquer interpretação que se queira fazer dele. O cuidado está sempre aí presente e subjacente como a constituição do ser humano. Falar do ser humano sem falar do cuidado não é falar do ser humano. (BOFF, 2013, p. 54). ${ }^{7}$

O cuidado possibilita ao humano ser e se realizar enquanto pessoa, encontrando aí sua “quietude”. O ser humano se constrói na relação com o outro. Nestes termos, Heidegger (1989, p. 170) afirma que "na base desse ser-no-mundo determinado pelo com, o mundo é sempre o mundo compartilhado com os outros. O mundo da pre-sença é mundo compartilhado. O ser-em é ser-com os outros”. O ser humano se compreende na relação com os outros e, sem dúvida, na relação com o mundo que o rodeia. O outro, e de forma mais ampla a sociedade e a cultura, interpela a todo instante sua liberdade, pedindo um posicionamento. Esta "copresença" do outro, enquanto sociedade e ambiente cultural, questiona seu modo de viver e promove seu desenvolvimento e amadurecimento humanos. "Estar-nomundo" supõe zelo com o cosmos e com os objetos, pois é de onde o humano retira seu sustento e desenvolve sua vida. "Estar-com-os-outros" aponta para o cuidado

\footnotetext{
${ }^{7}$ Leonardo Boff avança na explicitação e na necessidade do cuidado planetário, essencial para vivermos bem e resultado de um processo educacional inclusivo, porém, não será foco desta análise.
} 
com as relações pessoais, nas quais um auxilia o outro a ser sujeito. A atitude de ocupação com o cosmos e solicitude com os outros acaba gerando, para Heidegger, certa dose de preocupação e angústia, pois há ligação afetiva estabelecida.

Estar-no-mundo é estar-com-os-outros e, neste sentido, desde o início da vida, o ser humano necessita de alguém. "Para Winnicott, o início da vida é marcado pela experiência de dependência absoluta, momento em que o bebê não pode prescindir de alguém que dele se ocupe e com ele se preocupe.” (FRANÇA; ROCHA, 2015). O ser humano, neste momento inicial da vida, é extremamente dependente do outro. Entretanto, na construção de sua autonomia e no desenvolvimento de sua maturidade emocional, torna-se fundamental que o ser humano fique só. Aqui emerge uma situação paradoxal, pois "a base da capacidade de ficar só reside nessa capacidade de ficar só na presença do outro”. (FRANÇA; ROCHA, 2015). Nesta relação de troca afetiva, um transmite ao outro mais do que possa ter consciência. ${ }^{8}$ Esta relação interpessoal, com nuances e cuidados distintos, acompanha o ser humano por toda sua vida e o possibilita irromper na existência como sujeito e construtor de história.

Nesta dinâmica existencial de cuidar e ser cuidado que emerge sua radical atividade: "somente porque recebeu cuidado, o ser humano pode cuidar de si mesmo e cuidar dos outros como atitude originária”. (BOFF, 2012, p. 58). Aqui se concentra o foco de nossa atenção e proposta educacional. Para Leonardo Boff (2012, p. 58), estas atitudes de ser cuidado e de cuidar "constitui a energia fontal e seminal que vai constituir, ao longo do tempo e do espaço, a humanidade do ser humano". Os valores humanitários que serão desenvolvidos no ser humano estão intrinsecamente ligados ao cuidado recebido e oferecido. Esta dimensão é essencial para que a pessoa siga os princípios éticos e atenda aos comportamentos morais ao longo de sua vida. Assim, "uma das funções do cuidado seria desenvolver a capacidade cuidadora, em uma mutualidade de cuidados que culmina em uma atitude ética diante do outro e do mundo" (FRANÇA; ROCHA, 2015). O ser humano

\footnotetext{
8 "Os adultos transmitem às crianças muito mais do que supõem, e não têm consciência de como o transmitem." (KUPFER, 2007, p. 216 apud SERRALHA, 2011).
} 
está aberto a mudanças e ao aprendizado. Crianças e adolescentes, quando cuidadas, desenvolvem habilidades para cuidar. Isto poderá se contrapor às suas experiências familiares e, mesmo, às da sociedade à sua volta. $\mathrm{O}$ ambiente saudável e propício para boas relações interpessoais na escola auxiliará as crianças e os adolescentes a desenvolverem valores humanitários em suas vidas.

O desenvolvimento da saúde emocional estimulará a atenção e propiciará maior assimilação do conhecimento, sobretudo se aliado a uma metodologia ativa. Kelso defende a tese que "o cérebro do ser humano é fundamentalmente um sistema auto-organizativo formador de padrões, governado por leis não-lineares e dinâmicas". E continua afirmando que, "em vez de computador, nosso cérebro 'inhabita' ('dwelles') - ao menos por breves momentos - estados instáveis; e é quando transita por esses limiares de instabilidade que o cérebro pode realizar conexões flexíveis e rápidas”. (KELSO, 1995, p. 26 apud ASSMANN, 1998, p. 35). Kelso (2003) explica que "sistemas auto-organizados são como uma orquestra sinfônica que toca sem um maestro". Logo, a aprendizagem não é um amontoado sucessivo de coisas que vão se unindo, mas, nesta perspectiva, "trata-se de uma rede ou teia de interações neuronais extremamente complexas e dinâmicas, que vão criando estados gerais qualitativamente novos no cérebro humano" (ASSMANN, 1998, p. 36). Ao produzir esta reconfiguração no cérebro, envolvendo a corporeidade toda, o processo pedagógico torna-se profundamente significativo para os aprendentes, sejam professores ou alunos. A interação entre os que buscam o conhecimento e a tecnologia, aliados à metodologia adequada, possibilitará sempre novas sinapses. Sendo assim, a sociedade do conhecimento deve incentivar a relação entre processos cognitivos e processos vitais (eu-outro-meio ambiente), tornando o estímulo ao conhecimento e ao cuidado do que está à volta natural e afetivamente positivo.

Vera Lúcia do Amaral, ao trabalhar a complexa inter-relação entre forças fisiológicas e sociais no processo do ensino-aprendizagem, conclui articulando alguns autores clássicos: 
1. A experiência do sujeito, o contato com o meio social em que vive, tem mostrado que é fundamental para o estabelecimento de conexões sinápticas estáveis. Na verdade, a experiência modifica mesmo a estrutura da organização cerebral, evidenciando a sua plasticidade. A importância deste aspecto foi apontada por Vygotsky;

2. A transformação de conexões "lábeis" em conexões estáveis entre os neurônios vai depender em grande parte de que elas "encontrem sentido", ou seja, mostrem-se significativas e úteis. Tal busca de relações de sentido e significação já vinha sendo apontada por Ausubel;

3. Uma vez estabelecida a conexão, com seu uso frequente, ela tornase estável, acomoda-se, equilibra-se. O conceito de acomodação e equilibração já estava colocado por Piaget;

4. As motivac,ões e os afetos, como mecanismos básicos do ser humano, são modificados pela aprendizagem e são, também, impulsionadores desta, como já mostrava Kurt Lewin. (AMARAL, 2007, p. 14).

Todo este processo de relações e conexões se torna fundamental para a construção da subjetividade humana. A relação entre o "mundo externo" e o "mundo interno" possibilitará a organização de suas capacidades racionais, emocionais e imaginativas. Autores como Piaget, Vygotsky, Ausubel e Wallon mostraram a importância da emoção e da motivação no processo da cognição. Luis Carlos Restrepo chega a dizer que

não cabe dúvida de que o cérebro necessita do abraço para seu desenvolvimento, e as mais importantes estruturas cognitivas dependem deste alimento afetivo para alcançar um nível adequado de competência. Não devemos esquecer, como Leontiev destacou há bastantes anos, que o cérebro é um autêntico órgão social, necessitado de estímulos ambientais para seu desenvolvimento. Sem aconchego afetivo, o cérebro não pode alcançar seus ápices mais elevados na aventura do conhecimento. (RESTREPO, 2008, p. 34).

O abraço é expressão do afeto e o cérebro necessita dele para propiciar novas conexões neuronais. Afeto e ternura são essenciais no processo da aprendizagem, pois geram atitudes positivas e são fontes de energia para a mudança e para a transformação. A fábula do Cuidado ajuda a compreender que o ser humano é articulação entre corpo, espírito e afeto. ${ }^{9}$ Leonardo Boff nos apresenta esta fábula:

\footnotetext{
${ }^{9}$ A articulação entre corpo-psíquico-espírito pode ser aprofundada no texto sobre "Múltiplas dimensões do ser humano"; ver Panasiewicz (2011, p. 15-28).
} 
Certo dia, ao atravessar um rio, Cuidado viu um pedaço de barro. Logo teve uma ideia inspirada. Tomou um pouco do barro e começou a dar-lhe a forma de um ser humano. Enquanto contemplava o que havia feito, apareceu Júpiter. Cuidado pediu-lhe que soprasse espírito nele. O que Júpiter fez de bom grado. Quando, porém, Cuidado quis dar um nome à criatura que havia moldado, Júpiter o proibiu. Exigiu que fosse imposto o seu nome. Enquanto Júpiter e Cuidado discutiam, surgiu, de repente, a deusa Terra. Ela também quis conferir o seu nome à criatura, pois fora feita de barro, material do seu corpo. Originou-se então uma discussão generalizada. De comum acordo pediram a Saturno, o pai de todos os deuses e o senhor do tempo, para que arbitrasse a questão. Ele acedeu prontamente e tomou a seguinte decisão, que pareceu justa a todos: "Você, Júpiter, deu-lhe o espírito; receberá, pois, de volta o espírito quando essa criatura morrer. Você, Terra, deu-lhe o corpo; receberá, portanto, também de volta o seu corpo quando essa criatura morrer. Mas você, Cuidado, que foi quem, por primeiro, moldou a criatura, cuidará dela enquanto viver. E, uma vez que entre vocês há acalorada discussão acerca do nome, decido eu: esta criatura será chamada Homem, isto é, feita de húmus, que significa terra fértil. (BOFF, 2013, p. 55-56).

Esta composição literária mostra que a existência do ser humano é marcada pelas relações e que o afeto (Cuidado) é quem o acompanhará em toda a sua vida. Ele será, portanto, elemento essencial para a construção do sentido, possibilitando que o humano construa novas relações e amplie seu horizonte existencial. Emerge aqui a linguagem como promotora e articuladora destas relações. Dentre as várias formas, destacaremos a arte de dialogar como expressão da linguagem e condutora do aprofundamento de si no encontro com o outro. Como a linguagem pode transformar o ambiente educacional e articular cuidado e conhecimento?

\section{Linguagem como expressão do afeto e do conhecimento}

O ser humano é ser de linguagem..$^{10}$ Ela revela e oculta sua intimidade, aponta para símbolos, explícitos ou implícitos, conscientes ou inconscientes; elucida tanto a imanência quanto a transcendência de valores ou entidades e demarca a dimensão social e universal do humano. Esta expressão comunicativa possibilita troca de experiências, de ideias, de opiniões e leva a novas interações e construções de conhecimento, tanto pessoais quanto comunitárias, tanto existenciais quanto

\footnotetext{
${ }^{10}$ Para Heidegger (2014, p. 55), "de acordo com a sua Essência, a linguagem é a casa do Ser, edificada em sua propriedade pelo Ser e disposta a partir do Ser. Por isso urge pensar a Essência da linguagem numa correspondência ao Ser e como uma tal correspondência, isto é, como a morada da Essência do homem". É, portanto, onde o ser habita e se revela.
} 
planetárias. Há magia e mistério na linguagem humana, pois revela e, em certo sentido, oculta seu ser desconhecido. Ela habita e desvela o humano. Para Gusdorf (1970, p. 36), a linguagem "fornece a senha de entrada no mundo humano", pois ultrapassa aspectos orgânicos e adentra a dimensão intelectual e espiritual do mesmo. ${ }^{11}$

Enquanto expressão natural do humano, a linguagem se distingue da língua. Enquanto a linguagem aponta para a dimensão universal do humano, a língua identifica e classifica um grupo ou uma cultura, distinguindo-o dos demais, e sua diversidade resulta e expressa construções socioculturais. Trata-se, assim, de convenções e, portanto, caso alguém a desconheça, terá dificuldades para entrar em sintonia com outra pessoa. Daí a dificuldade em efetivar traduções, pois, mais que conhecer a língua formal, fundamental se faz conhecer as convenções, os dialetos culturais e, em alguns casos, aspectos existenciais para um mergulho no sentido. Língua e linguagem se distinguem teoricamente, mas se articulam na interioridade do humano, permitindo que se construam mundos com sentido ou se produzam conflitos e intolerâncias sem sentido.

Língua e linguagem abraçam a educação humana e proporcionam construções de afetos e desafetos. Fundamental se faz acentuar seus aspectos positivos, pois, mesmo em situações de conflito, as expressões podem levar à reconstrução das relações. O processo educacional, especificamente o ambiente escolar, torna-se essencial para que o ser humano compreenda e expresse a universalidade da linguagem ao mesmo tempo em que apreende e sistematiza as convenções da língua formal onde vive. Para além de aspectos técnicos e explorando a linguagem como possibilitadora do encontro interpessoal, emerge o diálogo. Para Buber, o ser humano está sempre em relação: a relação Eu-Tu e Eu-Isso, que ele as identifica como palavras-princípio. A primeira, Eu-Tu, aponta para a relação de abertura ao Outro, sem interesses, permitindo que um e outro se manifestem livremente; trata-se de relação dialógica, profundamente humanizadora. A segunda,

\footnotetext{
${ }^{11}$ Há muitos estudos apresentando a complexidade da linguagem, seja para o mundo humano ou mundo animal. No dicionário Logos, Michel Renaud (1991, p. 399-410) apresenta rápida linha do tempo mostrando a variedade de compreensão da linguagem humana ao longo da história.
} 
Eu-Isso, demarca interesses, é instrumental, e o Outro é usado como meios para fins; trata-se de relação não dialógica. Para ele, “a palavra-princípio Eu-Tu só pode ser proferida pelo ser em sua totalidade. A palavra princípio Eu-Isso não pode jamais ser proferida pelo ser em sua totalidade”. (BUBER, 2017, p. 51). Travamos, constantemente, a relação Eu-Isso, porém, a relação Eu-Tu gera humanização para ambas as partes. Entretanto, estas relações podem ser diferentes?

Alexandre Guilherme (2016) mostra a interação entre os princípios Eu-Tu e Eu-Isso e como um pode ser ativado pelo outro. O Eu-Tu pode se transformar em Eu-Isso quando, numa relação amorosa, instrumentalizamos o Outro. Ou quando os filhos transformam os pais em motoristas ou pagadores de contas; quando alunos veem nos professores serviçais ou professores veem nos alunos somente fonte de sustentação (Eu-Isso). Por outro lado, o Eu-Isso pode se tornar Eu-Tu quando permite que uma relação com um desconhecido se torne humanizante. Ao usar, por exemplo, o serviço de taxi e transformar a viagem em diálogo construtivo; quando, ao solicitar informações para uma secretária, a cordialidade conduz o momento (EuTu). A relação com o Outro, seja com pessoa próxima ou desconhecida, pode ser humanizante e edificadora, ou exploradora e discriminatória.

Neste sentido, todos os envolvidos no processo educacional escolar devem ficar atentos, pois, sabendo da distinção de relações entre Eu-Tu e Eu-Isso, torna-se fundamental estimular ambientes nos quais se maximize o princípio Eu-Tu. "O 'entre’, o ‘intervalo’, é o lugar de revelação da palavra proferida pelo ser do homem. Esse 'entre' é a própria palavra na sua força criadora de relação". (ZUBEN, 2008, p, 95). O "entre" torna-se ação recíproca que provoca o Eu e o Tu; ele é o lugar da formação dialógica, da relação propriamente dita. Treinar para saber conviver. Mais que isto, a educação deve propiciar ao ser humano aproveitar toda oportunidade de relação interpessoal para que se torne relação dialógica, ou seja, relação Eu-Tu.

Nesta articulação entre diálogo e educação, Guilherme e Morgan (2018) articulam as reflexões de Martin Buber e Paulo Freire e dizem: 
Martin Buber o compreende como professor-construtor de uma comunidade dialógica por desempenhar um papel fundamental na formação do caráter dos indivíduos. Paulo Freire desenvolve esta noção, defendendo o professor-político, o qual desempenha um papel central na formação de indivíduos críticos e na libertação dos oprimidos. (GUILHERME; MORGAN, 2018, p. 794).

As atitudes de professor-construtor e de professor-político perpassam a atividade docente na naturalidade de seu exercício, pois são construtores de pontes dialógicas ao mesmo tempo em que exercem ação política (homo politicus). Há mútua articulação destes termos elucidando que a construção de ações dialógicas no humano se faz com conscientização e valorização das pessoas. O ambiente escolar, e mais especificamente a sala de aula, torna-se, no dia a dia, lugar preferencial para a capacitação e o treinamento de habilidades, para que emerjam seres humanos saudáveis emocionalmente e competentes no exercício da cidadania.

Todo ambiente escolar deve estar impregnado desta concepção dialógica. Ela deve perpassar as disciplinas e a elaboração e execução dos projetos pedagógicos ao longo do ano acadêmico. As várias áreas do conhecimento também devem entrar em sintonia, exercer a relação Eu-Tu e estimular que o "entre" seja vivido entre professores-alunos-colaboradores. Diante de situações de discriminação, bullyings, preconceitos, de violência em geral, há necessidade de tomada de atitudes e de reflexões sobre a situação para que ela seja processada conscientemente pelas pessoas envolvidas e novas práticas sejam estimuladas. A violência intensifica a dimensão do "Isso" e anula a possibilidade do "Eu", pois "coisifica" e elimina o outro. Esta percepção, desenvolvida no ambiente educacional, estimula novos comportamentos e novas práticas no convívio social. Isto é o círculo hermenêutico do conhecimento em ação, pois articula prática e teoria estimulando novas teorias e novas práticas.

Todas as matérias são responsáveis por manter e estimular este cuidado nas relações interpessoais, mas há alguma que, por sua especificidade, poderia orquestrar esta sinfonia de diferentes instrumentos? Dentre as várias matérias, compreendemos que a disciplina Ensino Religioso poderia exercer papel estimulador e promotor destas construções, pois cuidar do humano e das relações 
em meio à diversidade é sua função primária. ${ }^{12}$ Esta proposição não exime ninguém, porém estimula este profissional no exercício da liderança e no cuidado com as humanidades, tanto na formulação do Projeto Político Pedagógico das escolas quanto em sua efetivação. ${ }^{13}$ As diferenças fazem parte de todas as relações, pois o humano é naturalmente único. Lidar com as diferenças exige habilidades, mas, sobretudo, disposição interior para desenvolvê-las. Dentre as diferenças que perpassam as humanidades no ambiente escolar, destacamos presença e concepções distintas de religiões e espiritualidades. Como lidar com tão ampla diferença e que, por sua natureza, toca no mais profundo do humano, ao revelar crenças e pertenças?

As religiões criam cosmovisões e as pessoas religiosas, de maneira geral, refletem estas visões de mundo. Podem ter expressões mais fechadas e alienantes, ou mais abertas e libertadoras: ambas refletem concepções teológicas, culturais e temporais distintas. A clareza de sua historicidade permite compreender que há movimentos no interior das religiões, como também pluralidade de interpretações. Elas não são uníssonas. Estas diferenças aparecem no ambiente educacional e desafiam os educadores. A todo o tempo aparecem oportunidades para exercer o cuidado. Trata-se de treinamento constante, pois a todo o momento há situações de diálogo. No instante em que emerge um conflito por divergência de opiniões - e mesmo por agressão física -, torna-se fundamental que este conflito seja mediado e compreendido pelas partes envolvidas. Parar a aula ou a atividade para discutir a questão não pode ser percebido como perda de tempo, mas ao contrário. O diálogo profícuo Eu-Tu legitima o "entre" e faz com que todos amadureçam como pessoas, avancem emocionalmente e fiquem mais disponíveis para o conhecimento. Várias são as formas de incentivar o desenvolvimento do "entre" e torna-se fundamental que o educador exercite esta função. Problematizar o conflito e desvendá-lo possibilita educar para a autonomia do educando de forma que os envolvidos criem

\footnotetext{
${ }^{12}$ Art. 33 da Lei 9475, de 1997, diz: “O ensino religioso, de matrícula facultativa, é parte integrante da formação básica do cidadão e constitui disciplina dos horários normais das escolas públicas de ensino fundamental, assegurado o respeito à diversidade cultural religiosa do Brasil, vedadas quaisquer formas de proselitismo." (PRESIDÊNCIA..., 1997).

13 "O Ensino Religioso, nesse sentido, objetiva ser tempo e espaço de conexão, ou para usar uma palavra mais clara, apesar de gerar suspeita etimológica, de religação de saberes e sabedorias." Paulo Agostinho N. Baptista (2015, p. 117), ao recuperar aspectos históricos da disciplina, fala da formação docente e da importância da disciplina no ambiente escolar.
} 
“chaves de leituras” para a resolução de conflitos e não fiquem na dependência da intervenção alheia. No caso do conflito religioso, pode ser oportunidade para ampliar a compreensão dos alunos envolvidos e despertar para a diversidade presente, que deve naturalmente ser respeitada.

De maneira pedagógica, há possibilidades de tornar o diálogo inter-religioso uma prática e mobilizar todo o ambiente escolar para a percepção das diferentes maneiras de crer. Saber das religiões ou espiritualidades presentes na escola e do seu entorno, e mesmo com os que se declaram sem religião, pode ser momento oportuno para novos conhecimentos e exercício do diálogo. Há quatro níveis ou formas de realizar o diálogo inter-religioso, a saber: o existencial, o ético, o místico e o teológico. ${ }^{14}$ Compreender melhor estes níveis e organizar diálogos inter-religiosos no ambiente escolar, longe de proselitismos, favorecerá: a) conhecimento mútuo; b) respeito e acolhida da diferença; c) exercício do diálogo permanente; d) capacitação para a tolerância.

Educar para a tolerância deve se configurar tarefa essencial do processo educacional. Tolerar não significa neutralidade nem ter de aguentar o outro, mas, deve ser compreendida como atividade profundamente dialógica. Implica acolhida e reconhecimento do outro enquanto outro, ou seja, em suas especificidades e diferenças peculiares, que o tornam "um outro" de mim mesmo. Educar para saber conviver com a diferença e saber que "entre" o Eu e o Tu existe a potencialidade de ocorrer uma relação dialógica, se ambos os lados permitirem. ${ }^{15}$

O diálogo inter-religioso pode ser exercício e treinamento para novas competências e emergências de novos cidadãos e de construção de nova sociedade. A tendência da sociedade globalizada e articulada pelas redes sociais e pela comunicação em suas diversas formas estimula o convívio com o diferente. $\mathrm{O}$ exercício do diálogo inter-religioso se faz importante em ambientes educacionais para que não emerjam discursos ou pessoas fundamentalistas e a relação Eu-Isso

\footnotetext{
${ }^{14}$ Uma apresentação dos níveis ou formas de diálogo inter-religioso e uma sugestão de organização podem ser vista em Panasiewicz (2003, p. 39-54).

${ }^{15}$ Dentre as várias discussões sobre o termo "tolerância", Paulo Menezes (1996) apresenta boa sistematização.
} 
não seja estimulada no trato interpessoal. Em contrapartida, sejam aprofundadas as relações Eu-Tu e práticas dialógicas construídas em sua totalidade, permanecendo o convite aberto para que o ser humano mantenha relações dialógicas no convívio interpessoal e nos ambientes sociais.

\section{Conclusão}

A educação escolar é espaço privilegiado para o desenvolvimento da socialização e articulação dos saberes. Educar para a vida e saber lidar com clareza e determinação com os desafios que constantemente se apresentam são princípios de sabedoria da convivência interpessoal. Dentre os vários benefícios que toda pesquisa traz para as pessoas envolvidas e que são compartilhados para análise, debate e ganhos coletivos, esta pesquisa trouxe dois, em particular. Primeiramente, a percepção de que a realização de projetos da escola e o conhecimento desenvolvidos pelas disciplinas em sala de aula devem estar articulados. Importante saber da especificidade e identidade de cada um, porém a clareza dos pontos de contato entre eles propicia ganhos para o saber, para os relacionamentos e para a nova consciência que emerge de práticas coletivas. $O$ segundo aspecto foi a percepção da necessidade de uma pedagogia do cuidado e do conhecimento em todo ambiente educacional. Quando juntamos o afeto (cuidado) com os saberes ministrados nas disciplinas (conhecimento), o empenho dos participantes deste processo e o desenvolvimento das atividades acontecem com naturalidade e ganho para todos. Ao sermos envolvidos pelo cuidado, gratuitamente respondemos na mesma sintonia. Isto se aplica a todo ser humano: ao que vive em centros urbanos, na periferia, em situação de violência ou em ambientes rurais, pois é do humano amar e ser amado.

Educar para a tolerância, para a cultura da paz e para a responsabilidade social deve ser tarefa e missão de todo ambiente escolar. Ser professor-construtor e professor-político é, a todo instante, um convite desafiador aos professores: envolve aproveitar toda oportunidade, seja para fortalecer o esforço e empenho no avanço do cuidado com o outro, seja para provocar reflexões e tomada de atitudes em prol 
da valorização da vida, em situações de discriminação e violência. A todo tempo vivemos relações Eu-Tu e Eu-Isso; importante estimular os educandos para que sempre sejam experimentadas relações dialógicas, e não relações de objetificação do outro. O "entre" torna-se possibilidade de aprendermos a ser afetuosos (ou não) ou propiciar que outros sejam. O exercício do diálogo inter-religioso pode se tornar oportunidade e lugar de treinamento, ao participar dos projetos escolares a serem implementados ou de discussões no interior da sala de aula. Educar para o cuidado e para o conhecimento se efetiva no envolvimento de professores, alunos e colaboradores, ao se comprometerem com a formação humana, social e intelectual, a partir da articulação entre afeto e saberes.

\section{REFERÊNCIAS}

AMARAL, Vera Lúcia. Psicologia da educação: como se aprende - o papel do cérebro. Natal: EDUFRN, 2007. Disponível em: http://www.ead.uepb.edu.br/arquivos/cursos/Geografia_PAR_UAB/Fasciculos\%20\%20Material/Psicologia_Educacao/Psi_Ed_A07_J_GR_20112007.pdf. Acesso em: 10 jul. 2019.

ASSMANN, Hugo. Reencantar a educação. Petrópolis: Vozes, 1998.

BAPTISTA, Paulo Agostinho N. Ciências da Religião e Ensino Religioso: o desafio histórico da formação docente de uma área de conhecimento. Rever, São Paulo, ano 15, n. 2, p. 107125, jul./dez. 2015. Disponível em: file:///Users/roberlei/Downloads/26189-68445-1SM\%20(2).pdf. Acesso em: 20 jun. 2019.

BOFF, Leonardo. O cuidado necessário. 2. ed. Petrópolis: Vozes, 2013.

BRISTOTT, Maria I.; KRIPKA, Rosana M. L.; BEDIN, Silvio A. Cuidado e educação: uma proposta alternativa para a construção da cultura do bem viver. RevistAleph, ano XIV, $\mathrm{n}$. 28, p. 152-169, jul. 2017. Disponível em:

http://www.revistaleph.uff.br/index.php/REVISTALEPH/article/view/538/374. Acesso em: 10 jun. 2019.

BUBER, Martin. Eu e tu. São Paulo: Centauro Editora, 2017. 
CARVALHO, Izabella Faria; FERREIRA; Adilson do Nascimento. Análise espacial como instrumento para a seleção de escolas, campo de trabalho de pesquisa sobre liberdade religiosa, educação e tolerância. Anais do Congresso da Soter, p. 1508-1513. 2018. Disponível em: http://www.soter.org.br/anais/31.pdf. Acesso em: 20 ago. 2019.

CRUZ; Camila C. M.; GONÇALVES, Dinéia F.; PANASIEWICZ, Roberlei. Diálogo interreligioso e educação: a construção de um ambiente escolar que reconheça e valorize a alteridade. Anais da Soter. 2018. p. 658-664. Disponível em:

http://www.soter.org.br/anais/31.pdf. Acesso em: 10 ago. 2019.

FRANÇA, RAFAELA M. P; ROCHA, Zeferino. Por uma ética do cuidado na psicanálise da criança. 2015. Disponível em:

http://www.scielo.br/scielo.php?script=sci_arttext\&pid=So103-65642015000300414. Acesso em: 10 jul. 2019.

FREIRE, Paulo. Pedagogia do oprimido. 23. ed. São Paulo: Paz e Terra, 1974.

GUILHERME, Alexandre A. Alex Guilherme e o diálogo de e com Martin Buber.

[Entrevista cedida a Nilda Stacanela]. Conjectura, Caxias do Sul, v. 21, n. 1, p. 216-230, jan./abr. 2016. Disponível em:

https://www.researchgate.net/publication/324280606_Alex_Guilherme_e_o_dialogo_de _e_com_Martin_Buber. Acesso em: 12 ago. 2019.

GUILHERME, Alexandre A.; MORGAN, W. John. Refletindo sobre o papel do professor: Buber, Freire e Gur-Ze'ev. Educação e Realidade, Porto Alegre, v. 43, n. 3, p. 783-798, jul./set. 2018. Disponível em:

http://www.scielo.br/scielo.php?script=sci_arttext\&pid=S2175-

62362018000300783\&lng=en\&nrm=iso\&tlng=pt. Acesso em: 12 ago. 2019.

GUSDORF, Georges. A fala. Porto: Edições Despertar, 1970.

HEIDEGGER, Martin. Ser e tempo. 3. ed. Petrópolis: Vozes, 1989.

HEIDEGGER, Martin. Sobre o humanismo. Rio de Janeiro: Tempo Brasileiro, 1967.

HERNANDÉZ, Fernando. Transgressão e mudança na educação: os projetos de trabalho. Porto Alegre: Artmed, 1998.

KELSO, J. A. S. A auto-organização e os caminhos da consciência. Jornal da Unicamp, Campinas, ed. 212, 12 a 18 maio, 2003. Disponível em:

https://www.unicamp.br/unicamp/unicamp_hoje/ju/maio2003/ju212pg5a.html. Acesso em: 12 ago. 2019. 
KISHIMOTO, Tizuko M. Apresentação: cultura como meta John Dewey. Disponível em: http://www.scielo.br/scielo.php?script=sci_arttext\&pid=S0103-73072011000200014. Acesso em: 25 maio 2019.

MENEZES, Paulo. Filosofia e tolerância. Síntese Nova Fase, Belo Horizonte, v. 23, n. 72, p. 5-11, 1996.

MINAYO, Maria Cecília de Souza. Conceitos, teorias e tipologias de violência: a violência faz mal à saúde. In: MINAYO, Maria Cecília de Souza. Violência e saúde. Rio de Janeiro: Fiocruz, 2006. Disponível em: http://www1.londrina.pr.gov.br/dados/images/stories/Storage/sec_mulher/capacitacao_r ede\%20/modulo_2/205631-conceitos_teorias_tipologias_violencia.pdf\&gt. Acesso em: 10 set. 2017.

PANASIEWICZ, Roberlei. Múltiplas dimensões do ser humano. In: SANCHEZ, Wagner Lopes; BAPTISTA, Paulo Agostinho Nogueira (org.). Teologia e sociedade: relações, dimensões e valores éticos. São Paulo: Paulinas, 2011. p. 15-28.

PANASIEWICZ, Roberlei. Níveis ou formas de diálogo inter-religioso: uma leitura a partir da teologia cristã. Horizonte, Belo Horizonte, v. 2, n. 3, p. 39-54, 2003. Disponível em: http://periodicos.pucminas.br/index.php/horizonte/article/view/597. Acesso em: 10 jun. 2019.

PANASIEWICZ, Roberlei; BAPTISTA, Paulo Agostinho N.; BRAGA, Alex S.; CARNEIRO, Maria Emília A. Educação e cidadania: a formação humanista da juventude nos Projetos Político-Pedagógicos. Horizonte, Belo Horizonte, v. 10, n. 26, p. 399-431, abr./jun. 2012. Disponível em: http://periodicos.pucminas.br/index.php/horizonte/article/view/P.21755841.2012v10n26p399. Acesso em: 10 set. 2017.

PRESIDÊNCIA DA REPÚBLICA. Lei 9.475, de 22 de julho de 1997. Disponível em: http://www.planalto.gov.br/ccivil_03/leis/L9475.htm. Acesso em: 25 maio 2019.

RENAUD, Michel. Linguagem. In: CABRAL, Roque et al. Logos: enciclopédia lusobrasileira de filosofia. Verbo: Lisboa/São Paulo, 1991.

RESTREPO, Luis C. O direito à ternura. Petrópolis: Vozes, 1998.

SERRALHA, Conceição A. Ética do cuidado e ações em saúde e educação. 2011. Disponível em: http://pepsic.bvsalud.org/scielo.php?script=sci_arttext\&pid=S1679432X2011000100002\&lng=en\&tlng=en\#?. Acesso em: 10 jul. 2019.

ZUBEN, Newton A. von. A questão do inter-humano: uma releitura do Eu e Tu de Martin Buber. Síntese, Belo Horizonte, v. 35, n. 111, p. 87-110, 2008. 